\title{
Coherence of Our Best Scientific Theories
}

Park, Seungbae (2011). "Coherence of Our Best Scientific Theories", Foundations of Science 16 (1): 21-30.

Seungbae Park

Division of General Studies

Ulsan National Institute of Science and Technology

Republic of Korea

nature@unist.ac.kr

\begin{abstract}
Putnam (1975) infers from the success of a scientific theory to its approximate truth and the reference of its key term. Laudan (1981) objects that some past theories were successful, and yet their key terms did not refer, so they were not even approximately true. Kitcher (1993) replies that the past theories are approximately true because their working posits are true, although their idle posits are false. In contrast, I argue that successful theories which cohere with each other are approximately true, and that their key terms refer. My position is immune to Laudan's counterexamples to Putnam's inference and yields a solution to a problem with Kitcher's position.
\end{abstract}

Keywords: Coherence, Kitcher, Laudan, Putnam, Success, Scientific Realism.

\section{Introduction}

Consider such scientific theories as the special theory relativity, the theory of evolution, the theory of DNA, the kinetic theory of gases, and the theory of electrons. They are successful, i.e., they have high explanatory, predictive, and manipulative powers. Putnam (1975) claims that it would be a miracle if a successful theory is not even approximately true, and its key term does not refer. It follows that a successful theory is approximately true, and that its key term refers. Thus, from the premise that a scientific theory is successful, Putnam draws the conclusion that it is approximately true and its theoretical entity is real. Putnam's argument for scientific realism (realism from now on) triggered a debate between realists and antirealists. The most forceful criticism against Putnam's argument was put forward by Laudan (1981), and the most influential defense of realism from Laudan's attack was advanced by Kitcher (1993). The aim of this paper is to analyze Laudan's critique of realism and to introduce a new strategy to overcome his criticism. My strategy will be shown to be better than Kitcher's, yielding 
an insight on which of the current scientific theories are the best, what properties they have in common, and what theoretical claims will survive scientific revolutions in the future.

\section{Laudan's Criticism}

Laudan (1981: 33) provides the infamous list of past theories to undercut the realist inference from the success of a theory to its approximate truth and the existence of its theoretical entity. The list consists of twelve past theories, such as the ether theory and the caloric theory of heat. They were successful, and yet their key terms did not refer, so they were not even approximately true. The ether theory is not even approximately true because its key term 'ether' does not refer, and that the caloric theory of heat is completely false because there is no such thing as caloric fluid. After providing the infamous list, Laudan claims that there is no necessary connection between success and approximate truth:

\footnotetext{
...there is no necessary connection between increasing the accuracy of our deep-structural characterizations of nature and improvements at the level of phenomenological explanations, predictions and manipulations. (ibid: 35 )
}

In the concluding section of his paper, Laudan claims that there are just too many counterexamples to the realist epistemology, i.e., realists cannot explain success in term of approximate truth and reference:

Their epistemology is confronted by anomalies which seem beyond its resources to grapple with. (ibid: 47-48).

Note that Laudan says that there are anomalies that realism cannot explain. He does not make the ambitious claim that successful current theories will turn out to be completely false. He only accuses the realists of "foreclosing the possibility that some future generation may come to the conclusion that some (or even most) of the central terms in our best theories are no more referential than was 'natural place,' 'phlogiston,' 'aether,' or "caloric"' (ibid: 42). In other words, he only suggests that it is possible that central terms of current theories might be nonreferring. He does not claim that it is likely that the central terms of current theories are nonreferring. In short, nowhere does he run the pessimistic induction against current theories.

Realists and antirealists alike in the philosophy of science literature, however, do 
not interpret Laudan as I do. Kitcher, Leplin, and Ladyman attribute the pessimistic induction to him:

\begin{abstract}
Laudan's use of the pessimistic induction from the history of science to discredit the claims to reference and truth of current science and to undermine a realist account of progress is the most sophisticated that I know. (Kitcher, 1993: 149)
\end{abstract}

He [Laudan] argues inductively that our current picture is unlikely, in retrospect, to have achieved referential success or approximate truth from the vantage point of future science, and that realism, according, has no application. (Leplin, 1997: 137)

The pessimistic meta-induction from the history of past theory change in science was originally proposed to confute the realist's claim that truth explains the success of science by showing that our best present and future theories are most likely false (Laudan [1981]). (Ladyman, 1999: 186)

I believe that the above three commentators are wrong to attribute the pessimistic induction to Laudan because his position is different from the pessimistic induction. The pessimistic induction asserts that current theories will turn out to be completely false. Laudan, however, is silent about the status of the current theories. He only asserts that there are counterexamples to the realist inference from success to approximate truth and reference. Stanford would agree with me on this account:

Laudan's case focuses on the related questions of truth and reference for our successful scientific theories: he uses the historical record to cast doubt on whether successful contemporary scientific theories are (even probably or approximately) true and whether their central theoretical terms refer. (Stanford, 2006: 142)

The pessimistic induction is an ambitious thesis, whereas Laudan's position is a modest one. They should be kept apart from each other because it is easier to refute an ambitious thesis than a modest one. In order to refute the ambitious thesis, we only need to show that the current theories are more successful than past theories. After all, if current theories are more successful than past theories, from the fact that successful past theories were completely false, it does not even inductively follow that successful current theories are completely false too. But the fact that the current theories are more successful than past theories does not refute Laudan's modest claim that there are counterexamples to the realist inference from success to approximate truth and 
reference. In any event, the target of this paper is Laudan's position, not the pessimistic induction.

\section{My Coherence Approach}

My reaction to Laudan's critique of realism is to argue that our best current theories are not in the same boat as the successful past theories on his list. Unlike the successful past theories, some current theories are not only successful but also cohere with each other. The intuitive idea of coherence is that two theories cohere with each other just in case an inference from one to the other is "to some degree truth-preserving" (BonJour: 1985: 96). Coherence is more than the absence of contradiction. Also, coherence admits of degree. Some theories loosely cohere, and others tightly cohere with each other. The notion of coherence of two theories can be cashed out in the following three ways, which are not intended to be exhaustive.

First, as Friedman (1981) notes, in science a theoretical structure is used to explain not only the phenomena it was designed to explain but also, in conjunction with other theoretical structures, other phenomena it was not designed to explain. For instance, the molecular hypothesis of gases explains not only gas laws but also other kinds of phenomena in conjunction with atomic theory:

\footnotetext{
...the hypothesis of molecular constitution, in conjunction with atomic theory, for example, helps us to explain chemical bonding, thermal and electrical conduction, nuclear energy, genetic inheritance, and literally hundreds of other phenomena. (Friedman, 1981: 7)
}

Friedman stresses that the molecular hypothesis of gases picks up additional confirmation from the areas where it works together with atomic theory. Now, Friedman's observation on theoretical explanation points to the direction in which a concept of coherence can be developed. Two theories cohere with each other if they have their own observational evidence, and work together to explain new phenomena.

Let me provide two more examples fitting the above definition. The theory of evolution and the theory of plate tectonics have their own independent observational evidence, and jointly explain new phenomena (Brody et al: 252-253). For example, why do some turtles in Brazil travel to an island in the middle of the Atlantic Ocean, risking their lives? Why don't they just stay in Brazil? The answer involves the theory of evolution and the theory of plate tectonics. Millions of years ago Brazil was only a stone's throw from the island, and the turtles laid eggs on the island to protect them from the mainland predators. As the continent and the island gradually drifted apart, the 
turtles mentally and physically adapted to the gradual increase of the distance. Notice that the two theories jointly explain the new phenomena. It is not the case that the theory of evolution or the theory of plate tectonics alone explains why the turtles travel to the island. They have to work together to explain the new phenomena. Also, the two theories have observational evidence other than the new phenomena.

Another example goes as follows: The theory of DNA and the electromagnetic theory have their own observational evidence, and work together to explain new phenomena. For example, why do we develop skin cancer when exposed to sunshine for a long time? According to a proffered theoretical explanation, ultraviolet radiation destroys DNA, and the destruction of DNA leads to skin cancer. Notice again that the theory of DNA or the electromagnetic theory alone could not yield such a theoretical explanation, and that the two theories have their own observational evidence other than skin cancer. So the theory of DNA and the electromagnetic theory cohere with each other.

Second, Boven and Hartmann observe that our confidence on something increases when the sources of information on it are independent of each other:

Coherence will play a confidence boosting role when the information sources are independent and partially reliable. (Boven and Hartmann, 2003: 604).

From their observation, we can say that scientific theories cohere with each other, if they, having been independently confirmed, are used to point to the same assertion about unobservables. In this sense, the kinetic theory of heat, the electro-chemical theory of electrolysis, and the electromagnetic theory cohere with each other. These theories were developed and confirmed by Maxwell, Faraday, and a host of other scientists in the $19^{\text {th }}$ century. Since 1815 , there were many attempts to calculate Avogadro's number: the number of molecules of an arbitrary gas contained in a given volume at a set temperature and pressure. It was Perrin, though, in the early $20^{\text {th }}$ century who determined it with reasonable accuracy. He used several independent theories, including the aforementioned three theories. What was remarkable was that they all pointed to the same number of molecules. As a result, the scientific community was finally fully persuaded of atomism. Note that the above three theories were independent of each other and independent of Perrin's experiments. It is not the case that they were revised in the early stages of their development in order to accommodate Perrin's experimental results. Thus, the three theories cohere with each other. 
Third, two theories cohere with each other, if they have their own observational evidence, and a component of one theory explains a component of the other theory. The theory of DNA asserts that all current organisms on the earth use the same genetic code (Sober, 1993: 41). The theory of evolution claims that there was a common ancestor for all current living organisms on earth. The statement that there was a common ancestor explains why all current terrestrial organisms use the same genetic code. Thus, the theory of evolution and the theory of DNA cohere with each other.

Let me say one more thing about coherence. Two theories may cohere with each other either directly or indirectly. Suppose that they stand in any of the foregoing three relations. Then, they directly cohere with each other. Now suppose that $\mathrm{T}_{1}$ directly coheres with $T_{2}$, and that $T_{2}$ directly coheres with $T_{3}$. Then, $T_{1}$ indirectly coheres with $T_{3}$. They do not cohere with each other as tightly as they do with the intermediary theory, $\mathrm{T}_{2}$. Still, they are more than merely consistent with one another. Now suppose that $\mathrm{T}_{1}$ and $\mathrm{T}_{3}$ also directly cohere with each other by standing in any of the foregoing three relations. Then, $\mathrm{T}_{1}, \mathrm{~T}_{2}$, and $\mathrm{T}_{3}$ cohere with each other both directly and indirectly. The theory of DNA directly coheres with the electromagnetic theory because they jointly explain new phenomena like skin cancer. The electromagnetic theory directly coheres with the kinetic theory of heat because they were used to calculate Avogadro's number. The kinetic theory of heat directly coheres with the theory of DNA because they jointly explain new phenomena like muscle contractions. ${ }^{1}$ So the three theories cohere with each other both directly and indirectly.

What follows from the fact that some successful current theories cohere with each other? First, they are different in kind from the past theories on Laudan's list. For example, one of the theories on the list is the humoral theory of medicine. It was developed in ancient Greece to explain diseases (Mason, 1962: 227). The theory postulated four distinct humors solely for the sake of explaining the medical phenomena. It is not clear if it cohered with other scientific theories. What is clear, though, is that its possible contemporary counterpart, the germ theory of disease, coheres with the theory of DNA, which in turn coheres with the theory of evolution, and which in turn coheres with the theory of plate tectonics.

Secondly, if success cries out for an explanation, so does coherence. A theory may not be successful. If it is, however, we may wonder what made it so. The same is true of coherence. Two independent theories may not explain a new phenomenon, and may not make the same claim about unobservables. A component of a theory may not explain a component of another theory. If they do these things, however, we may wonder what made them so. We need to come to terms with the questions: Why do two independently 
successful theories miraculously cohere with each other? What properties do they have in common that made them cohere with each other? The realist answer is that they are approximately true, and that their key terms refer.

The above considerations lead me to a new version of realism: Our best theories are the successful theories that cohere with each other. They are approximately true, and their key terms refer. Successful theories cohere with each other because they are both approximately true, and because their key terms refer. It would be a miracle if such theories are completely false, and if their key terms do not refer. Thus, approximate truth and reference provide the best explanation of success and coherence.

\section{Objections and Replies}

How would antirealists respond to my coherence approach? They might try to find in the history of science the successful past theories that cohered with each other, and yet their key terms did not refer, so they were not even approximately true. Such theories would serve as counterexamples undercutting my inference from success and coherence to approximate truth and reference. I welcome antirealists to come up with such theories from the history of science. We have, however, a reason to believe that they will fail. What drives the coherence of theories is the idea of atomism that all macroscopic objects are made out of the same kind of microscopic objects. If scientists believe that macroscopic objects are different kinds of things, and phenomena are not related to each other, there is not much room for scientific theories to interact with one another. A historical fact unfavorable to antirealists is that all the theories on Laudan's list were successful before the $20^{\text {th }}$ century, and that atomism was not fully accepted by the scientific community until the early $20^{\text {th }}$ century as said above.

Another objection available to the antirealists is to claim that the success of science does not need to be explained. Hence, the coherence of successful theories does not need to be explained either. Hendry, for instance, claims that antirealists could undermine Putnam's argument by rejecting "the call for explanation" (2001: S25). Hendry's point is that Putnam claims that approximate truth and reference explain success the best, so a successful theory is approximately true, and its key term refers. For the antirealists, however, success does not need to be explained, so we need not believe that a successful theory is approximately true, and that its key term refers. In Hendry's spirit, the antirealists may reject my coherence approach by saying that success and coherence need not be explained, so we need not believe that successful theories that cohere with each are approximately true, and their key terms refer. Thus, it is illegitimate to infer from success and coherence to approximate truth and reference. 
There are, however, three problems with Hendry's objection. First, suppose that astronomers explain astronomical phenomena in terms of an astronomical theory, and that biologists come along and claim that they do not feel the need to explain the astronomical phenomena. The astronomers would aptly point out that from the fact that the biologists do not feel the need to explain the astronomical phenomena, it does not follow that the astronomical theory they invoke is false. Whether the astronomical theory is true or false should be determined by how it is related to the astronomical phenomena. The epistemic reason for the astronomical theory is not undermined at all by the fact that some do not feel the need to explain the astronomical phenomena. Similarly, I argue that from the fact that antirealists do not feel the need to explain success and coherence, it does not follow that successful theories that cohere with each other are not even approximately true, and that their key terms do not refer. Whether the realist explanans is true or false should be determined by how it is related to its explanandum. The epistemic reason for approximate truth and reference is not undercut at all by the fact that antirealists do not feel the need to explain success and coherence.

Second, van Fraassen, a representative antirealist, tries to establish his contextual theory of explanation by saying that it accounts for rejections and asymmetries:

\footnotetext{
To be successful, a theory of explanation must accommodate, and account for, both rejections and asymmetries. I shall now examine some attempts to come to terms with these, and gather from them the clues to the correct account. (1980: 112)
}

Here, van Fraassen clearly feels the need to explain rejections and asymmetries. Then, why is it that rejections and asymmetries need to be explained but the success of science does not? Antirealists, who claim that success and coherence need not be explained, will face the challenge, whenever they try to explain something, to justify their seemingly arbitrary position that the phenomena they want to explain need to be explained but the phenomena the realists want to explain need not.

Third, Laudan, another leading antirealist, contends that the success of science needs to be explained. In fact, he explains it in terms of robust method as an alternative explanans to approximate truth:

Science is successful, to the extent it is successful, because scientific theories result from a winnowing process which is arguably more robust and more discriminating than other techniques we have found for checking our empirical conjectures about the physical world. (Laudan, 1984: 101) 
In other words, science is successful not because theories are approximately true but because scientists use a robust method to test them. Note that Laudan explains the success of science, which implies that he feels the need to explain it, so he cannot claim that success and coherence need not be explained.

Finally, van Fraassen would object that "nothing except evidence can give justification for belief" (1985: 255). In other words, only observational evidence provides support for a theory, so it is illegitimate to use a theory to justify another theory. Should we accept van Fraassen's claim that evidential support for a theory comes only from observations? He does not have an argument for it. In fact, it seems to be the starting point of the empiricist philosophy of science, which realists do not (have to) share. Hempel, for instance, claims that evidential support may come "from above":

Support may also come "from above"; that is, from more inclusive hypotheses or theories that imply the given one and have independent evidential support. (Hempel, 1966: 38)

For example, Balmer's formula received support from above when it was derived from Bohr's theory of the hydrogen atom. The theory of the hydrogen atom was supported by diverse evidence other than the spectroscopic measurements that lent inductive support to Balmer's formula. Hempel calls this kind of support "theoretical support" (1966: 39).

Some scientists do not share the empiricist's starting point either. Theoretical support played a dominant role in finally persuading the scientific community of atomism in the early $20^{\text {th }}$ century. As previously mentioned, what decisively convinced the scientists of the reality of atoms was the ways Avogadro's number were calculated. Perrin's experiments conclusively converted Ostwald, one of the most prominent and staunch opponents of atomism, to atomism (Salmon, 1984: 213-219). This historical episode suggests not only that theoretical support is powerful in persuading opposing scientists but also, more importantly, that theories receive evidential support "from sides," viz., from theories of neighboring fields. The independent theories involved in calculating Avogadro's number supported each other.

Antirealists might retort that theoretical support is in fact observational support in disguise, i.e., that all there is at the fundamental level is observational support. There are, however, three reasons to think that theoretical support is not reducible to observational support. The first reason can be found in the role of auxiliary assumptions in the context of confirmation in science. Suppose that a biologist investigates DNA with an electron microscope. Realists and empiricists alike agree that the images on the microscope 
support the theory of DNA. The empiricists might claim that the theory of DNA receives support solely from the images. But the realists would claim that it receives support not only from the images but also from the theory of electrons. Why do the realists think so? The images are evidentially inert without the theory of electrons. They are taken as evidence for the theory of DNA only via the theory of electrons. Unless the biologist has the knowledge of how the microscope works, he would have no idea of what the images prove. The theory of electrons is what arms the images with evidential power for the theory of DNA. Hence, the theoretical support is not reducible to the observational support.

Second, Hung (1997: 95-96) notes that a theory enhances the credibility of empirical generalizations. At least, scientists think so. Take, for instance, the empirical generalization that iron conducts heat. Previous experiences are the evidential support for the empirical generalization. But our confidence in the generalization increases when a theoretical account is given of why iron conducts heat. Here is an example from biology (Milius, 2000: 20-21). Scientists have been collecting data on the size of marine iguanas from the Galapagos Islands for eighteen years. The data suggested to them that the iguanas shrank and lengthened by as much as $20 \%$. But at first they dismissed the apparent shrinkage as errors in their measurements. They came to believe that the iguanas really shrank and lengthened only after they noticed that the shrinkage was correlated with ocean warming. The explanation of the shrinkage was that the iguanas graze in marine algal beds, and the algal beds thin out when the ocean gets warm, leaving the iguana starving. These examples support the idea that the credibility of observational beliefs comes in part from theories. Then, it is plausible that the credibility of a theory comes in part from other theories.

Third, in some cases, a theory "improves and corrects the empirical generalization that the theory is meant to explain" (Hung, 1997: 102). For instance, the kinetic theory of gases improved and corrected the equation of state of gases: PV=kT. Van der Waals derived what is now known as van der Waals's equation from the kinetic theory of gases. The new equation made slightly different predictions from the equation of state of gases: PV=kT. Experiments later confirmed the new equation (Hung, 1997: 102). A dramatic example where a theory corrects observational beliefs can be found in the distinction between primary and secondary qualities. It is atomism that led Newton and Locke to believe that secondary qualities are not inherent in bodies. Empiricists are right that observational beliefs are capable of correcting theories. But the reverse is true as well. Theories are also capable of correcting observational beliefs. It is not the case that theories are always at the receiving end of corrections. 
On the basis of the foregoing three reasons, I conclude that theoretical support is something over and above observational support. If this is right, a theory, having independent observational evidence, is capable of supporting another theory. Thus, support for a theory comes not only from below but also from sides and above. The idea of theoretical support meshes well with my contention that coherence has an evidential value and undermines van Fraassen's view that only observational evidence is capable of supporting a theory.

\section{Difference between My Coherence Approach and Kitcher's Approach}

Laudan's criticism against realism elicited huge responses from realists. Kitcher's response (1993: 140-149) has been the most influential one in the literature. Psillos (1996 and 1999, Chapters 5 and 6) and Leplin (1997: 141-152) largely follow Kitcher's lead on this matter. Kitcher argues that successful past theories on Laudan's list are approximately true, given that their working posits are true, although their idle posits are false. A working posit is a constituent of a theory that is severely tested by observations, that survives scientific revolutions, and that scientists have confidence in the truth of. An idle posit, on the other hand, is a component of a theory that is not severely tested by observations, that does not survive scientific revolutions, and that scientists have no confidence in. For example, a working assumption of the ether theory is the claim that light is a transverse wave, and an idle assumption of the theory is the claim that ether is a medium of light transmission. Psillo's historical case study includes the caloric theory and the ether theory, and Leplin's study includes Newton's theory of motion.

A problem with Kitcher's approach is that it is hard to distinguish between working and idle posits of current theories, although it is relatively easy to distinguish between working and idle posits of past theories in retrospect. Ladyman puts the problem as follows:

The trouble with this approach (that also besets Kitcher and Psillos) is how to make the distinction between eliminable and ineliminable components of a theory principled and not just an ad hoc strategy for coping with the refutation of realism by history. (Ladyman, 1999: 187)

What Ladyman calls eliminable components are idle posits that are eliminated after a scientific revolution, and ineliminable components are working posits that survive a scientific revolution. 
The coherence approach offers some principled criteria to separate working posits from idle ones. First, if two theoretical claims work together to explain new phenomena, they are working posits. In this sense, it is a working posit that species have evolved by natural selection, and that continents move around. The working posits are not just approximately true but completely true. Second, if two theoretical claims are explanatorily connected with one another, they are working posits. In this sense, it is a working posit that there was a common ancestor, and that all current organisms on the earth use the same genetic code. Third, theoretical entities are sufficiently proved to be real if the postulated interaction between them explains new phenomena. In this sense, X-rays, molecules, and DNA could be legitimately claimed to be real. Thus, Kitcher's distinction between working and idle posits along with my coherence approach tells us what components of current theories are true, and what theoretical entities of current theories are sufficiently proved to be real.

My coherence approach not only overcomes the difficulty of Kitcher's approach but also is in a stark contrast with it. Kitcher's strategy can be summed up as an attempt to do justice to the past theories on Laudan's list, for it claims that they are approximately true contra Laudan, given that their working posits are true. The coherence approach, on the other hand, can be characterized as an attempt to do justice to the current theories, for it claims that they differ from the past theories on Laudan's list in an important respect, viz., they are not only successful but also cohere with one another. It must be emphasized that my coherence strategy and Kitcher's strategy are not mutually exclusive. They rather complement each other, helping us to have a better diachronic picture of science. They are individually an incomplete portrayal of what parts of science are trustworthy.

\section{Conclusion}

General philosophy of science has operated so far under what I call the individualist tradition. Philosophers paid attention to a scientific theory in itself and to its relation to observations rather than to its relation to other theories. The topics discussed under this tradition include the pessimistic induction, the problem of underdetermination, the nature of scientific explanation, the theory-ladenness of observation, the structure of scientific theory, and so on. A problem with the individualist tradition is that it missed an important aspect of science: Scientific theories interact with each other.

It is now time, I believe, to move onto what I call the interactionist tradition. Under this tradition, philosophers of science will exhibit how scientific theories interact with each other, developing rigorous concepts to reveal and describe the interplay of 
theories in a more fine-grained manner than is done in this paper. As a result, we will have a better grasp of what current science looks like and how it will unfold in the future. Besides, the research achievements in the interactionist tradition will cast new light on the traditional topics discussed in the individualist tradition. For instance, I speculate that a theory which coheres with other theories yields a better explanation of phenomena than a theory which is merely consistent with other theories. It requires, however, a lot of space to present examples that justify my speculation. In any event, I believe that interaction is an important means to boost our confidence on a theory in current science.

End Note

${ }^{1}$ See Yanagida (2001: 64) on how the two theories jointly explain muscle contractions.

\section{References}

BonJour, L. (1985). The Structure of Empirical Knowledge. Cambridge, MA: Harvard University Press.

Bovens, L. and S. Hartmann (2003). "Solving the Riddle of Coherence." Mind Vol. 112, pp. 601-633.

Brody, E. and Brody, A. (1997). The Science Class You Wish You Had...: The Seven Greatest Scientific Discoveries in History of Science and the People Who Made Them. New York: The Berkeley Publishing Group.

Friedman, M. (1981). “Theoretical Explanation”, in Richard Healey, (ed.), Reduction, Time, and Reality: Studies in the Philosophy of Natural Science. Cambridge: Cambridge University Press.

Hempel, C. (1966). Philosophy of Natural Science. Englewood Cliffs, NJ: Prentice-Hall, Inc.

Hendry, R. (2001). “Are Realism and Instrumentalism Methodologically Indifferent?” Philosophy of Science (68) (Proceedings), pp. S25-S37 
Hung, E. (1997). The Nature of Science: Problems and Perspectives. Belmont, CA: Wadsworth Publishing Company.

Kitcher, Philip (1993). The Advancement of Science: Science without Legend Objectivity without Illusion. New York: Oxford University Press.

Ladyman, J. (1999). Review of Leplin's A Novel Defense of Scientific Realism. British Journal for the Philosophy of Science, 50, pp. 181-188.

Laudan, L. (1981). “A Confutation of Convergent Realism.” Philosophy of Science, 49, pp. 19-49.

(1984). "Explaining the Success of Science: Beyond Epistemic Realism and Relativism." in James Cushing, C.F. Delaney, and Gary Gutting (eds.), Science and Reality. Notre Dame: University of Notre Dame Press, pp. 83-105.

Leplin, J. (1997). A Novel Defense of Scientific Realism. New York: Oxford University Press.

Mason, S. (1962). A History of the Sciences. New York: A Simon \& Schuster Mcmillan Company.

Milius, S. (2000). “Famine Reveals Incredible Shrinking Iguanas.” Science News, Jan.

Psillos, S. (1996). "Scientific Realism and the Pessimistic Induction." Philosophy of Science (Proceedings), pp. S306-S314. (1999). Scientific Realism: How science tracks truth. New York: Routledge.

Putnam, H. (1975). "Realism in Mathematics and Elsewhere." Philosophical Papers Vol. 1., Cambridge University Press.

Salmon, W. (1984). Scientific Explanation and the Causal Structure of the World. Princeton, NJ: Princeton University Press.

Sober, E. (1993). Philosophy of Biology. Boulder, CO: Westview Press. 
Stanford, K. (2006). Exceeding Our Grasp: Science, History, and the Problem of Unconceived Alternative. New York: Oxford University Press.

van Fraassen, B. (1980). The Scientific Image. Oxford: Oxford University Press.

(1985). "Empiricism in the Philosophy of Science." in Images of Science.

Churchland, P. and Hooker, C. (1985). (eds.), Chicago: The University of Chicago Press.

Yanagida, T. (2001). “Muscling In.” Scientific American, July. 